\title{
Elaboration and Characterization of AuCl Semiconductor Nanocrystals Embedded in KCl Single Crystals
}

\author{
Fouzia Zehani $^{1^{*}}$, Miloud Sebais ${ }^{2}$, Hanane Zaioune ${ }^{1}$ \\ ${ }^{1}$ Laboratoire d'Etude des Matériaux (LEM), Département de Physique, \\ Facultés des Sciences Exactes et des Sciences de la Nature et de la Vie, Université de Jijel, Wilaya de Jijel, Algeria \\ ${ }^{2}$ Laboratoire de Cristallographie (LC), Université de Mentouri-Constantine, Wilaya de Constantine, Algeria \\ Email: ${ }^{*}$ zehanifouzia@yahoo.fr
}

Received April 10, 2012; revised May 11, 2012; accepted June 8, 2012

\begin{abstract}
In this work, we investigated the structural and the optical properties of $\mathrm{AuCl}$ semiconductor nanocrystals embedded in $\mathrm{KCl}$ single crystals. The $\mathrm{AuCl}$ nanocrystals were obtained by doping the $\mathrm{KCl}$ crystalline matrix with gold using the Czochralski method. The X-ray diffraction showed the formation of the $\mathrm{AuCl}$ nanocrystals in $\mathrm{KCl}$ with a tetragonal structure. The average radius of the $\mathrm{AuCl}$ nanocrystals is estimated using the Scherrer formula. The photoluminescence spectra presented a band emission situated at $580 \mathrm{~nm}$ leading to the formation of the $\mathrm{AuCl}$ nanocrystals within $\mathrm{KCl}$.
\end{abstract}

Keywords: AuCl; Semiconductor Nanocrystals; X-Ray Diffraction; Photoluminescence

\section{Introduction}

Semiconductor nanocrystals embedded in wide gap matrices, such as alkali halides $[1,2]$ have in recent years a great interest for both fundamental research and technical application. From the technological point of view, the main motivation for studying nanocrystals is to search new applications by controlling their physical properties as a function of size [3]. The nanocrystals are characterized by a dominant surface effect and they have a considerable surface/volume [4]. In that respect, the optical properties of semiconductor considerably change when their sizes become comparable to the bulk Bohr radius of exciton [3]. This change permits to get the quantum confinement of the electronic excitations [5]. The confinement in three dimensions of the exciton could be at the origin of strong nonlinear properties, which make them suitable materials for use in laser devices.

Gold(I) chloride $(\mathrm{AuCl})$ belong to the family of elements I-VII having semiconductor properties, was the subject of little studies. The optical properties of $\mathrm{AuCl}$ were studied by Claude Schwab et al. [6] and T. N. Silukova et al. [7]. They showed that the luminescence of the gold monochloride has a narrow band and a broad band situated respectively at $472.2 \mathrm{~nm}(2.62 \mathrm{eV})$ and 632 $\mathrm{nm}(1.96 \mathrm{eV})$. But their crystallographic properties were studied by E. M. W. Janssen et al. They found that the $\mathrm{AuCl}$ has a body-centered tetragonal structure with a space group $14_{1} /$ amd $[8]$.

${ }^{*}$ Corresponding author.
The aim of this work is to elaborate and study the structural and the optical properties of $\mathrm{AuCl}$ nanocrystals embedded in a $\mathrm{KCl}$ crystalline lattice; which is a dielectric material and transparent in the visible range. It is the range of optical response of $\mathrm{AuCl}$ nanocrystals. The characterization of $\mathrm{AuCl}$ nanocrystals in $\mathrm{KCl}$ has been studied by using the $\mathrm{X}$-ray diffraction and the photoluminescence (PL).

\section{Experimental}

The samples of $\mathrm{KCl}$ single crystals doped $\mathrm{AuCl}$ nanocrystals are elaborated using the Czochralski method, which consists of melting the gold thin films deposited on pure $\mathrm{KCl}$ pastilles. The growth process is performed by using a seed oriented [100]. The obtained single crystals have cylindrical shape and transparent colour. The single crystals are cleaved perpendicularly to the crystallographic direction [100]. The cleavage permits to obtain samples with $1 \mathrm{~mm}$ thickness. The thermal treatment of samples is performed at $650^{\circ} \mathrm{C}$ during 3 hours. After the annealing, the samples are cooled slowly at room temperature.

The crystalline structure was analysed with X-ray diffraction (XRD) by a Bruker D8 Advanced diffractometer system with $\mathrm{Cu}$ irradiation $\left(\lambda_{k \alpha}=1.54056 \AA\right)$ at $40 \mathrm{kV}$ and $40 \mathrm{~mA}$ in the $2 \theta$ range $\left(10^{\circ}-80^{\circ}\right)$. The photoluminescence (PL) spectra were measured with a Jobin-Yvon spectrofluorometer Fluorolog-3 using a Xenon lamp (450 W). 


\section{Results and Discussion}

\subsection{X-Ray Diffraction}

Figure 1 exhibits the X-ray diffraction of pure $\mathrm{KCl}$ samples. We observe two very intense peaks situated at $2 \theta=$ $28.37^{\circ}$ and $2 \theta=58.68^{\circ}$, corresponding to (200) plane and its harmonic (400) of $\mathrm{KCl}$ single crystals, as identified by using JCPDS file 41-1476.

$\mathrm{X}$-ray diffraction of $\mathrm{KCl}$ doped $\mathrm{AuCl}$ nanocrystals after annealing at $650^{\circ} \mathrm{C}$ for $3 \mathrm{~h}$, is showed in Figure 2. The spectrum shows the intense peaks of $\mathrm{KCl}$ single crystals and two diffraction peaks with a weak intensity, situated at $2 \theta=31.74^{\circ}$ and $2 \theta=65.83^{\circ}$. These peaks are attributed respectively to (211) and (422) planes of $\mathrm{AuCl}$ tetragonal structure with a space group $I 4_{1} /$ amd, comparing with the literature data of JCPDS file 30-0603. We note that the $\mathrm{AuCl}$ presents a preferential orientation along (211) and (422) planes, because of the oriented growth of $\mathrm{KCl}$ single crystals obtainedby the Czochralski method. We observe that the (400) peak of $\mathrm{KCl}$ is very intense that (200) comparing with those of spectrum of pure $\mathrm{KCl}$. This change may be due to doping of the $\mathrm{KCl}$ matrix by the $\mathrm{AuCl}$.

A slight shift of the $\mathrm{AuCl}$ peak angular positions towards higher angles can be noticed in comparison to the standard position indicated in the JCPDS file 30-0603.
This shift may be attributed to the contraction of the $\mathrm{AuCl}$ nanocrystals cells in $\mathrm{KCl}$ lattice [9].

Therefore, X-ray diffraction results confirm the formation and the embedding of $\mathrm{AuCl}$ nanocrystals in $\mathrm{KCl}$ matrix.

We assume that the shape of $\mathrm{AuCl}$ nanocrystal embedded in $\mathrm{KCl}$ was spherical. The average radiuses $(R)$ of $\mathrm{AuCl}$ were estimated using Scherer's formula [10]:

$$
D=2 R=\frac{0.9 \lambda}{\Delta(r a d) \cos \theta}
$$

where:

$D$ is the average diameter of the nanocrystals, $\lambda$ is the wavelength of the $\mathrm{X}$-ray radiation,

$\theta$ is the Bragg angle diffraction,

$\Delta$ is the full-width at half-maximum (FWHM) of the peak.

The average radius of $\mathrm{AuCl}$ nanocrystals in $\mathrm{KCl}$ corresponding to each diffracting plan is reported in Table 1. We note a large dispersion of $\mathrm{AuCl}$ nanocrystals size in $\mathrm{KCl}$. It is varied between 3.4 and $18.7 \mathrm{~nm}$.

\subsection{Photoluminescence}

PL spectra of pure $\mathrm{KCl}$ and $\mathrm{KCl}$ doped $\mathrm{AuCl}$ nanocrystals after annealing at $650^{\circ} \mathrm{C}$ for $3 \mathrm{~h}$ and excited with $\lambda_{e x}$

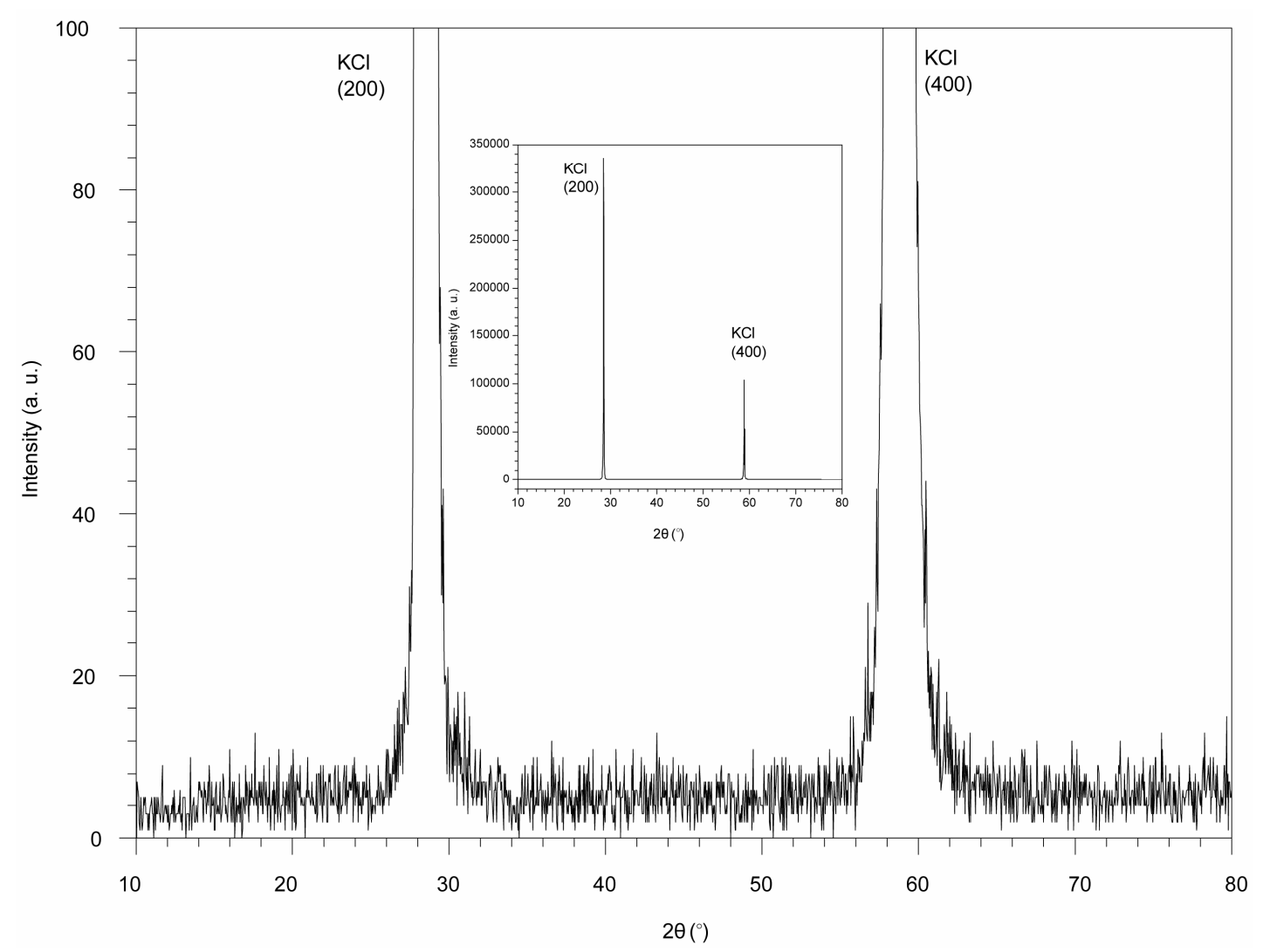

Figure 1. X-ray spectrum of pure KCl single crystals. 


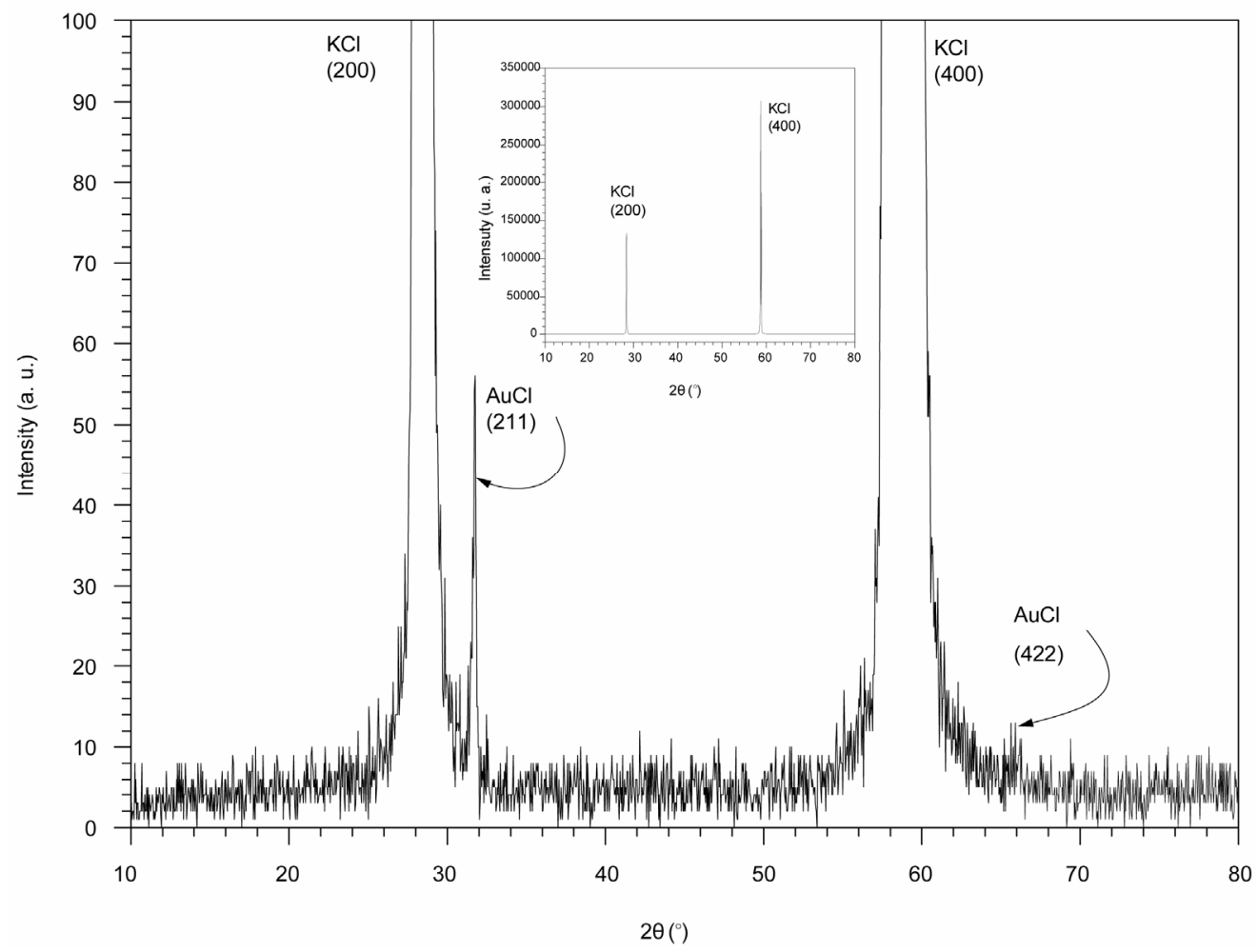

Figure 2. X-ray spectrum of $\mathrm{KCl}$ single crystals doped $\mathrm{AuCl}$ after annealing at $650^{\circ} \mathrm{C}$ for $3 \mathrm{~h}$.

$=300 \mathrm{~nm}$ at room temperature, are reported in Figure 3 . Indeed, for the spectrum ofpure $\mathrm{KCl}$ single crystals (Figure 3(a)), noemission bandcould be detected. However, the spectrum of $\mathrm{KCl}$ doped $\mathrm{AuCl}$ (Figure 3(b))

Table 1. Nanocrystal sizes of AuCl calculated from XRD.

\begin{tabular}{cccc}
\hline $2 \theta\left(^{\circ}\right)$ & $(h k l)$ & $\Delta\left(^{\circ}\right)$ & $R(\mathrm{~nm})$ \\
\hline 31.74 & $(211)$ & 0.22 & 18.7 \\
65.83 & $(422)$ & 1.36 & 3.4 \\
\hline
\end{tabular}

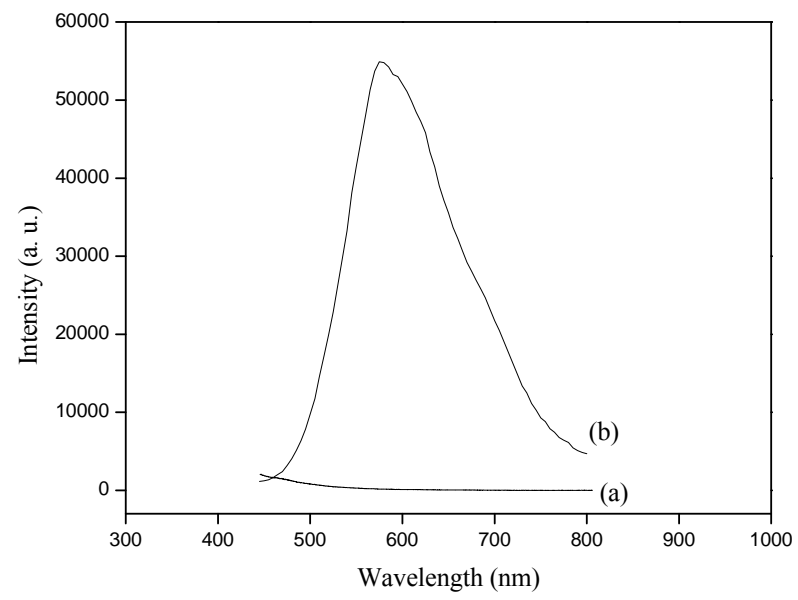

Figure 3. PL spectra $\left(\lambda_{e x}=360 \mathrm{~nm}\right)$ of: (a) Pure KCl and (b) KCl doped AuCl nanocrystals. shows a emission band centered at $580 \mathrm{~nm}(2.14 \mathrm{eV})$. We assign this band to $\mathrm{AuCl}$ nanocrystals with a shift from the bulk equal $52 \mathrm{~nm}(0.18 \mathrm{eV})$ [6]. The enlargement of this band can be explained by the presence of size dispersion of $\mathrm{AuCl}$ nanocrystals inside $\mathrm{KCl}$ (Table 1).

\section{Conclusion}

$\mathrm{KCl}$ single crystals doped $\mathrm{AuCl}$ nanocrystals were prepared by the Czochralski method. Structural characterization by XRD shows the formation of $\mathrm{AuCl}$ nanocrystals in $\mathrm{KCl}$ with a tetragonal structure. However, the PL measurements exhibit the characteristic emission band of $\mathrm{AuCl}$ nanocrystals situated at $2.14 \mathrm{eV}(0.18 \mathrm{eV}$ shift from bulk of $\mathrm{AuCl}$ ).

\section{REFERENCES}

[1] T. Itoh, Y. Iwabuch and M. Kotaoka, "Study on the Size and Shape of $\mathrm{CuCl}$ Microcrystals Embedded in AlkaliHalide Matrices and Their Correlation with Excitons Confinement," Physica Status Solidi (b), Vol. 145, No. 2, 1988, pp. 567-577. doi:10.1002/pssb.2221450222

[2] T. Itoh, Y. Iwabuch and T. Kirihara, "Size-Quantized Excitons in Microcrystals of Cuprous Halides Embedded in Alkali-Halide Matrices," Physica Status Solidi (b), Vol. 146, No. 2, 1988, pp. 531-543. doi: $10.1002 /$ pssb. 2221460215

[3] A. I. Ekimov, "Optical Properties of Semiconductor Quan- 
tum Dots in Glass Matrix," Physica Scripta, Vol. 1991, 1991, pp. 217-222. doi:10.1088/0031-8949/1991/T39/033

[4] A. Ekimov, "Growth and Optical Properties of Semiconductor Nanocrystals in a Gass Matrix," Journal of Luminescence, Vol. 70, No. 1-6, 1996, pp. 1-20.

[5] A. I. Ekimov, A. L. Efros, M. G. Ivanov, A. A. Onushchenko and S. K. Shumilov, "Donor-Like Exciton in Zero-Dimension Semiconductor Structures," Solid State Communications, Vol. 69, No. 5,1989, pp. 565-568. doi:10.1016/0038-1098(89)90242-1

[6] C. Schwab, et al., "Propriétés Optiques de $\mathrm{AuCl}$ aux Basses Temperatures," Comptes Rendus de l'Académie des Sciences, 1967, pp. 1739-1742.

[7] T. N. Silukova, P. A. Babin, S. F. Voroparev and V. G. Plekhanov, "Luminescence of Excitons in Gold Monochloride," Optics and Spectroscopy, Vol. 46, No. 2, 1979, pp. 218-219.

[8] E. M. W. Janssen, J. C. W. Folmer and G. A. Weigers, "The Preparation and Crystal Structure of Gold Monochloride, AuCl," Journal of the Less Common Metals, Vol. 38, No. 1, 1974, pp. 71-76. doi:10.1016/0022-5088(74)90204-5

[9] M. Samah, H. Khelfane, M. Bouguerra, A. Chergui, M. A. Belkhir and S. Mahtout, "Optical Responses of AlkaliHalide Matrix ( $\mathrm{NaCl})$-Doped Silver," Physica E, Vol. 23, No. 1-2, 2004, pp. 217-220. doi:10.1016/j.physe.2004.03.009

[10] H. Benelmadjat, B. Boudine, O. Halimi and M. Sebais, "Fabrication and Characterization of Pure and $\mathrm{Sn} / \mathrm{Sb}$ Doped ZnO Thin Films Deposited by Sol-Gel Method," Optics \& Laser Technology, Vol. 41, No. 5, 2009, pp. 630-633. doi:10.1016/j.optlastec.2008.09.011 